\title{
Angiotensin II receptor blocker attenuates overexpression of vascular endothelial growth factor in diabetic podocytes
}

\author{
Eun-Young Lee ${ }^{1}$, Myung Sook Shim ${ }^{2}$ \\ Mi Jin $\mathrm{Kim}^{3}$, Sae Yong Hong ${ }^{1}$ \\ Young Goo Shin ${ }^{2}$ and Choon Hee Chung ${ }^{2,4}$ \\ ${ }^{1}$ Department of Internal Medicine and \\ Clinical Research Institute \\ Soonchunhyang University Cheonan Hospital \\ Cheonan, Korea \\ ${ }^{2}$ Department of Internal Medicine \\ Yonsei University Wonju College of Medicine \\ Wonju, Korea \\ ${ }^{3}$ Department of Internal Medicine \\ Konkuk University College of Medicine \\ ${ }^{4}$ Corresponding author: Tel, 82-33-741-0506; \\ Fax, 82-33-731-5884; E-mail, cchung@wonju.yonsei.ac.kr
}

Accepted 6 January 2004

Abbreviations: RT-PCR, reverse transcription-polymerase chain reaction; VEGF, vascular endothelial growth factor

\begin{abstract}
VEGF expressed in glomerular podocytes, is known to increase vascular permeability to macromolecules. Angiotensin II can stimulate the release of VEGF, and the protective effects of angiotensin II antagonist against diabetic glomerular injury suggest that the angiotensin Il-induced VEGF is an important pathogenetic mechanism in the development of proteinuria during diabetic nephropathy although this mechanism is not fully understood. In this study, the changes of VEGF expression was examined in the experimental diabetic nephropathy to determine whether these changes were modified by renoprotective intervention by blockers of angiotensin II receptors. The streptozotocininduced diabetic rats were treated with L-158,809, a blocker of angiotensin II receptors, for 12 weeks. Age-matched rats with L-158,809 served as controls. RT-PCR and immunohistochemistry were used to assess and quantify gene and protein expression of VEGF. A progressive increase in urinary protein excretion was observed in diabetic rats. Glomerular VEGF expression was significantly higher in diabetic rats than in the control groups, with a significant reduction in glomerular
\end{abstract}

VEGF expression and proteinuria in $L-158,809$ treated diabetic rats. VEGF mRNA was also significantly higher in diabetic kidneys than in the control groups, with a significant reduction in VEGF mRNA in L-158,809-treated diabetic kidneys. These results demonstrates that VEGF expression is significantly increased in diabetic podocytes, and angiotensin II receptor antagonist attenuated these changes in VEGF expression and prevented the development of proteinuria in vivo. Attenuation of increased VEGF expression in podocytes could contribute to the renoprotective effects of angiotensin II receptor antagonists in diabetic nephropathy.

Keywords: angiotensin II receptor blocker; diabetes mellitus; diabetic nephropathy; podocyte; vascular endothelial growth factor

\section{Introduction}

Diabetic nephropathy is a leading cause of end-stage renal disease and accounts for significant morbidity and mortality among individuals with diabetes mellitus. In spite of many studies focused on the pathogenesis of diabetic nephropathy (Ha et al., 1997), the mechanism of hyperpermeability of the urinary filtration barrier to macromolecules including proteins is not fully understood.

Vascular endothelial growth factor (VEGF) is a potent cytokine that markedly increases vascular permeability to macromolecules (Gilbert et al., 2000). Hyperpermeability of the urinary filtration barrier to protein, which is an early characteristic of diabetic nephropathy, might be associated with VEGF overexpression. Angiotensin II could increase glomerular permeability (Blantz and Gabbai, 1987) in diabetes mellitus. The protective effects of blockers of angiotensin II receptors against the progression of diabetic nephropathy (The EUCLID Study Group, 1997) suggest that angiotensin II-induced VEGF is an important pathogenetic mechanism in the development of proteinuria in the course of diabetic nephropathy. Treatment of diabetic rats with angiotensin II receptor blocker reduces diabetes-associated retinal changes in VEGF mRNA expression and vascular permeability (Nagisa et al., 2001). Nevertheless, the regulation of expression of VEGF following the administration of 
angiotensin II receptor blocker in diabetic kidney has not yet been determined.

Podocytes cover the outer aspect of the glomerular basement membrane via foot processes, and modified tight junctions between adjacent cells form the slit diaphragm. This unique structure is specially designed to allow filtration, and represents the final barrier to proteins entering the urinary space (Kriz et al., 1994; Mundel and Kriz, 1995). Podocytes are the major synthesizers of VEGF in the mature kidney (Tsuchida et al., 1999). The expression of VEGF is increased in podocytes in diabetic rats and human (Cooper et al., 1999; Cha et al., 2000). Increased glomerular permeability due to VEGF might result in proteinuria in the diabetic kidney. Thus, it is reasonable to speculate that podocytes are responsible for the upregulation of VEGF in diabetic milieu, and is involved in the increase of glomerular permeability presented by proteinuria.

This study investigated VEGF expression in diabetic rat kidney in vivo, which is the main source of VEGF. We also explored whether an angiotensin II receptor blocker, L-158,809, has preventive effects on podocyte VEGF expression in diabetic nephropathy.

\section{Materials and Methods}

\section{Animals}

Thirty-two male Sprague-Dawley rats aged 8 weeks were assigned randomly to receive streptozotocin (Sigma, St. Louis, MO) at a dose of $60 \mathrm{mg} / \mathrm{kg}$ intraperitoneally (diabetics, $n=16$ ) or citrate buffer alone (controls, $n=16$ ). Both diabetic and control rats were further selected at random to receive either a blocker of angiotensin II type-1 receptors, L-158,809 (kindly gifted by Merck \& Co., NJ), at a dose of 5 $\mathrm{mg} / \mathrm{kg}$ body weight/day, or untreated drinking water. All rats were given free access to standard rat food and drinking water. Only streptozotocin-treated animals with plasma glucose concentrations above 12 $\mathrm{mmol} / \mathrm{l}$ were considered diabetic and included in the study. Diabetic rats received subcutaneous insulin (Humulin-N ${ }^{\circledR}$, Eli Lilly \& Co., IN) daily to maintain body weight and maximize the survival rate. Plasma glucose concentrations were checked by glucose oxidase technique every week. Body weight and systolic blood pressure were measured by tail-cuff plethysmography (Bunag, 1973) at 0, 8, and 12 weeks after streptozotocin treatment. Twenty-four-hour urine protein excretions were measured by an Autokit Micro TP on a Hitachi 7170 analyzer (Hitachi, Japan) (Lynch et al., 1996) from each animal at 0,8 , and 12 weeks after streptozotocin treatment. Twelve weeks after induction of diabetes, the rats were killed and their kidneys were harvested. The research protocol was approved by the animal ethics committee of the Yonsei University Wonju College of Medicine (Wonju, Korea).

\section{Glomerular volume}

General pathologic analysis was performed using 5$\mu \mathrm{m}$-thick sections stained with hematoxylin and eosin. The glomerular cross-sectional area (Area) was measured in 40 glomerular profiles per rat using a microcomputer imaging device (SIS, Münster, Germany), and glomerular volume $\left(V_{G}\right)$ was calculated according to the method of Weibel and Gomez (Lane et al., 1992): $V_{G}=$ Area $^{1.5} \times(1.38 / 1.01)$, where 1.38 is a shape coefficient for a sphere and a 1.01 is the size distribution coefficient assuming a coefficient of variation of $10 \%$.

\section{Semiquantitative reverse transcription-polymerase chain reaction (RT-PCR) of VEGF transcripts}

Total RNA was extracted using TRIzol LS reagent (Life Technologies. Gaithersburg, MD) and the cDNA was synthesized by a reverse transcription reaction of $2 \mu \mathrm{g}$ of total RNA with oligo-(dT) primers (Life Technologies). Next, $2 \mu \mathrm{L}$ cDNA was amplified by Taq DNA polymerase and the PCR profile consisted of initial denaturation at $94^{\circ} \mathrm{C}$ for $3 \mathrm{~min}$, followed by 35 cycles of denaturation at $94^{\circ} \mathrm{C}$ for $30 \mathrm{~s}$, annealing at $58^{\circ} \mathrm{C}$ for $30 \mathrm{~s}$, extension at $72^{\circ} \mathrm{C}$ for $90 \mathrm{~s}$, and extension at $72^{\circ} \mathrm{C}$ for $7 \mathrm{~min}$. Rat VEGF primers, which amplify three splicing variants of rat VEGF mRNA $\left(V E G F_{120}, V E G F_{164}\right.$, and $\left.V E G F_{188}\right)$, were used. The expected lengths of their PCR products are 330 base pairs (bp) for VEGF 120,462 bp for VEGF 164 , and 514 $\mathrm{bp}$ for $V E G F_{188}$. The nucleotide sequences of each primer are as follows: sense 5'-GACCCTGGTGGACATCTTCCAGGA-3' and antisense 5'-GGTGAGAGGTCTAGTTCCCGA-3'. $\beta_{2}$-microglobulin was also amplified as an internal control. The nucleotide sequences of the primers are as follows: sense 5'-CAGATCTGTCCTTCAGCAAG-3' and antisense 5'-GGAGTAAACTGGTCCAGATG-3'. Different numbers of PCR cycles were performed and plotted against the densitometry measurements of the resulting PCR products to define the range in which cycle number was linearly related to the amount of PCR-amplified product. Next, $10 \mu \mathrm{l}$ PCR reaction product were separated by electrophoresis through a $1.5 \%$ agarose gel with ethidium bromide. PCR product bands, visualized by ultraviolet light, were scanned at 300 dots per inch and densitometric analysis was done with the National Institutes of Health Image 1.61 software with available macro and linear regression analyzer. To confirm the identity of VEGF cDNA product, each of the electrophoresed PCR bands was extracted with a DNA extraction kit (Qiagen, Valencia, CA) and sequenced using 
an $A B I$ automated DNA sequencing system ( $A B I$ Genetic Analyzer 310; PRISM, Branchburg Park, NJ). Quantitation of the VEGF mRNA expression was corrected by $\beta_{2}$ microglobulin.

\section{Immunohistochemistry}

The kidney tissues were fixed in $4 \%$ paraformaldehyde and subsequently embedded in paraffin for light microscopy. Serial $5-\mu \mathrm{m}$-thick sections were obtained, air dried, and heat fixed on slides. The sections were deparaffinized with xylene and rehydrated in alcohol at a graded series of concentrations. Endogenous peroxidase was inactivated using $3 \%$ hydrogen peroxide in methyl alcohol for $30 \mathrm{~min}$. The kidney sections were incubated for $1 \mathrm{~h}$ at room temperature with mouse monoclonal anti-VEGF antibody (1:100) (\#sc-7269, Santa Cruz Biotechnology, CA), followed by a polymer detection kit (\#87-8963, Zymed, South San Francisco, CA) for $20 \mathrm{~min}$ at room temperature. The expression of VEGF was assessed by densitometric evaluation of the images by computer-assisted image analysis. Data are expressed as the percentage optical density relative to control kidneys, which were assigned a value of 100 . All analyses were performed with the observer blind to the animal study group.

\section{Statistics}

Results are expressed as means \pm standard deviations unless stated otherwise. Data were analyzed by ANOVA with multiple comparisons between groups using the Tukey test. A $P$ value less than 0.05 was considered statistically significant.

\section{Results}

\section{Animal data}

Plasma glucose was higher in diabetic rats, and unaffected by $L-158,809$ treatment. Body weight was lower in diabetic rats than in control animals, and was not influenced by L-158,809 treatment. No significant difference in blood pressure was observed between control and diabetic groups (Table 1). A progressive increase in urinary protein excretion was observed in diabetic animals. In L-158,809-treated diabetic rats the 24-h level of urinary protein was similar to that in control animals and less than that in untreated diabetic rats (Figure 1). The glomerular volume in untreated diabetic rats was higher than that in control rats, and may have been reduced by $L-158,809$ (the difference was not statistically significant) (Table 1).

\section{VEGF mRNA expression}

Expression of VEGF and $\beta_{2}$-microglobulin $\mathrm{mRNA}$ in 4 groups was observed on RT-PCR. Three isoforms of VEGF mRNA were expressed and VEGF 164 was the major isoform in all 4 groups. In control rats, low levels of VEGF isoforms were expressed. However, the untreated diabetic rats revealed high levels of VEGF isoforms (Figure 2). In L-158,809-treated diabetic rats the high levels of VEGF isoforms was

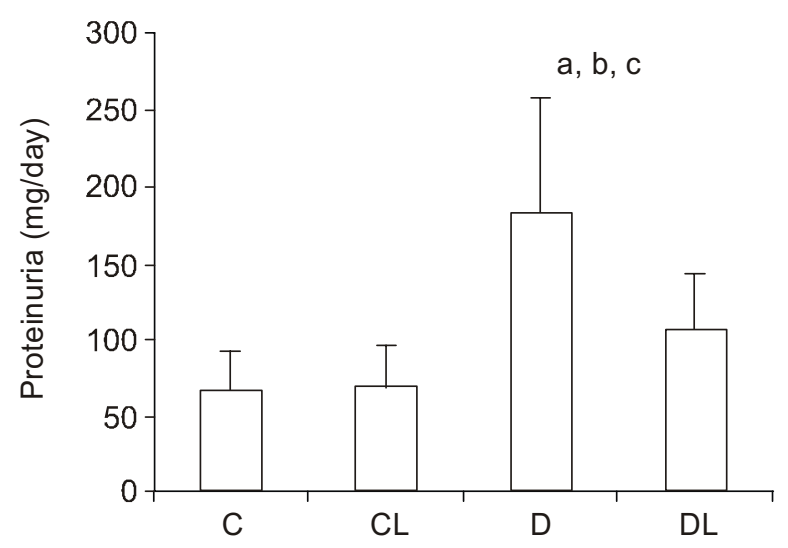

Figure 1. Proteinuria in control rats $(C)$, control rats treated with L-158,809 (CL), diabetic rats (D), and diabetic rats treated with L-158,809 (DL). The proteinuria was significantly higher in diabetic rats than in control rats, with a significant reduction in urinary protein excretion in L-158,809-treated diabetic rats. ${ }^{\mathrm{a} P}<0.05$ vs. $C,{ }^{\mathrm{b}} \mathrm{P}<$ 0.05 vs. $\mathrm{CL},{ }^{\mathrm{C}} \mathrm{P}<0.05$ vs. $\mathrm{DL}$.

Table 1. Clinical characteristics of rats 12 weeks after the induction of the study.

\begin{tabular}{lcccc} 
& $C(n=8)$ & $C L(n=8)$ & $D(n=8)$ & $D L(n=8)$ \\
\hline Body weight $(\mathrm{g})$ & $382.5 \pm 28.5$ & $350.5 \pm 23.9$ & $287.5 \pm 60.6^{\mathrm{a}, \mathrm{b}}$ & $322.5 \pm 64.3$ \\
Plasma glucose $(\mathrm{mmol} / \mathrm{l})$ & $6.2 \pm 0.2$ & $7.8 \pm 0.2$ & $14.6 \pm 3.2^{\mathrm{a}, \mathrm{b}}$ & $16.5 \pm 3.5^{\mathrm{a}, \mathrm{b}}$ \\
Systolic blood pressure $(\mathrm{mmHg})$ & $113.1 \pm 7.0$ & $109.5 \pm 2.7$ & $123.8 \pm 11.9$ & $119.3 \pm 13.6$ \\
Glomerular volume $\left(\times 10^{6} \mathrm{\mu m}^{3}\right)$ & $1.36 \pm 0.13$ & $1.26 \pm 0.17$ & $1.47 \pm 0.13$ & $1.40 \pm 0.15$
\end{tabular}

Data are shown as meantstandard deviation. C, control rats, $C L$, control rats treated with $L-158,809, D$, diabetic rats, DL, diabetic rats treated with $L-158,809$. a $P<0.05$ vs $C,{ }^{b} P<0.05$ vs. $C L$. 


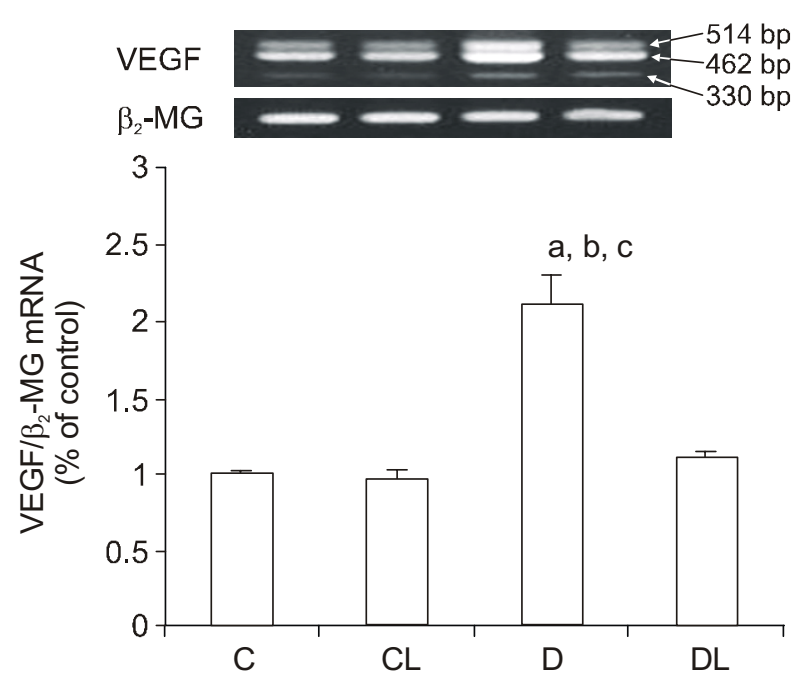

Figure 2. Expression of vascular endothelial growth factor (VEGF) and $\beta_{2}$-microglobulin $\left(\beta_{2}-M G\right)$ mRNA in kidney was analyzed by semiquantitative reverse transcription-polymerase chain reaction (PCR). The expected lengths of their PCR products are 330 base pairs (bp) for

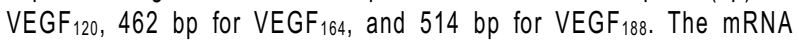

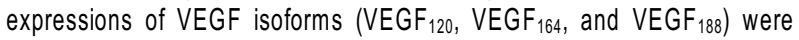
significantly increased in diabetic rats (D) than in control rats (C). In diabetic rats treated with $L-158,809$ (DL), the high levels of VEGF isoforms was decreased to that in $C$ and less than that in $D$. Expression of $\beta_{2}-M G$ was identified at nearly constant levels. ${ }^{a} P<$ 0.05 vs. $C,{ }^{b} P<0.05$ vs. $C L,{ }^{c} P<0.05$ vs. $D L$.

decreased to that in control animals and less than that in untreated diabetic rats (Figure 2).

\section{Immunohis tochemistry}

The expression of glomerular sVEGF was significantly higher in diabetic rats than in control rats, with a significant reduction in urinary protein excretion and glomerular podocyte VEGF expression in L-158,809treated diabetic rats (Figure 3 ).

\section{Discussion}

This study demonstrates that the expression of VEGF by podocytes is significantly increased in diabetic rats, and that this increase is completely abolished by treatment with a blocker of angiotensin II receptors, which also prevented the development of proteinuria in vivo. Our findings provide in vivo evidence of an angiotensin II-VEGF axis within the diabetic kidney, especially in glomerular podocytes.

Proteinuria is the initial and major symptom of diabetic nephropathy, and is the result of increased glomerular permeability (Parving et al., 1985). The expression of VEGF is increased in the diabetic kidney in association with hyperfiltration, proteinuria, and glomerular hypertrophy (Cooper et al., 1999), and these conditions are suppressed by the blocking of VEGF (de Vriese et al., 2001). Renal expression of VEGF receptors is also increased in experimental diabetic rats (Cooper et al., 1999). Since podocytes are the major producers of VEGF within the glomeruli (Kretzler et al., 1998; Cooper et al., 1999) and podocyte injury underlies proteinuria in diabetes (Nelson et al., 1997; Pagtalunan et al., 1997), regulation of VEGF expression in the podocytes may provide novel insight into the pathogenesis of diabetic nephropathy.

The mechanisms leading to upregulation of VEGF in diabetic glomerular injury are still not well understood. Several factors implicated in the pathogenesis of diabetic nephropathy have been shown to increase VEGF expression. High glucose levels directly increase VEGF expression in podocytes via protein kinase C-dependent mechanisms (Hoshi et al., 2002). The persistent expression of VEGF in the diabetic kidney may be related to the effects of advanced glycated end products that accumulate in diabetic tissues over weeks to months (Tsuchida et al., 1999). Of particular relevance to our study is that angiotensin II also stimulates the expressions of VEGF and VEGF receptors (Otani et al., 1998).

There are considerable evidences that the intrarenal renin-angiotensin system plays an important role in diabetic nephropathy. Angiotensin-converting enzyme inhibitors and blockers of angiotensin II receptors can attenuate progressive glomerulosclerosis in diabetes. Because the agents that interfere with the action of angiotensin II may decrease glomerular injury without altering glomerular pressure, it has been suggested that angiotensin II has direct effects on glomerular cells so as to induce sclerosis independent of its hemodynamic actions. Thus, it is possible that the effects of angiotensin converting enzyme inhibition on proteinuria and VEGF expression, as shown in our study, do not follow a reduction in systemic blood pressure. The presence of a local system distinct from a systemic reninangiotensin system has been established in the podocytes, where the presence of all components of reninangiotensin system, including its receptors, has been identified (Pavenstadt, 2000). Increased VEGF expression in diabetic podocytes was blocked by angiotensin II receptor antagonist in the present study. Taken together, these findings support the hypothesis that the milieu of diabetes increases angiotensin II, which results in stimulation of VEGF secretion, leading to increased vascular permeability to protein, thus producing proteinuria. This may be an important mechanism linking hyperglycemia, angiotensin II and VEGF in the pathogenesis of diabetic nephropathy (Leehey et al., 2000). Angiotensin II can stimulate the release of VEGF from human vascular tissues. VEGF is a potent cytokine 
A
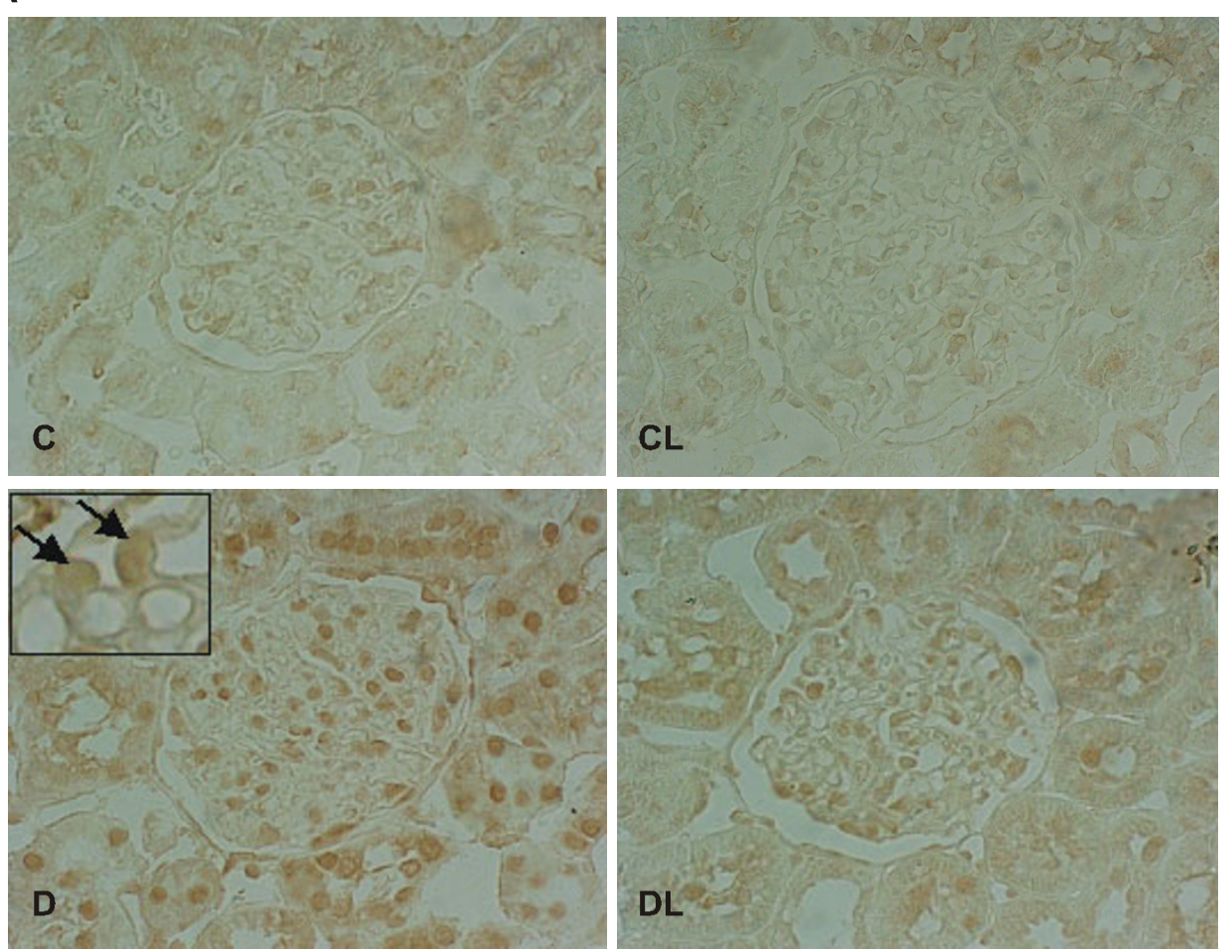

B

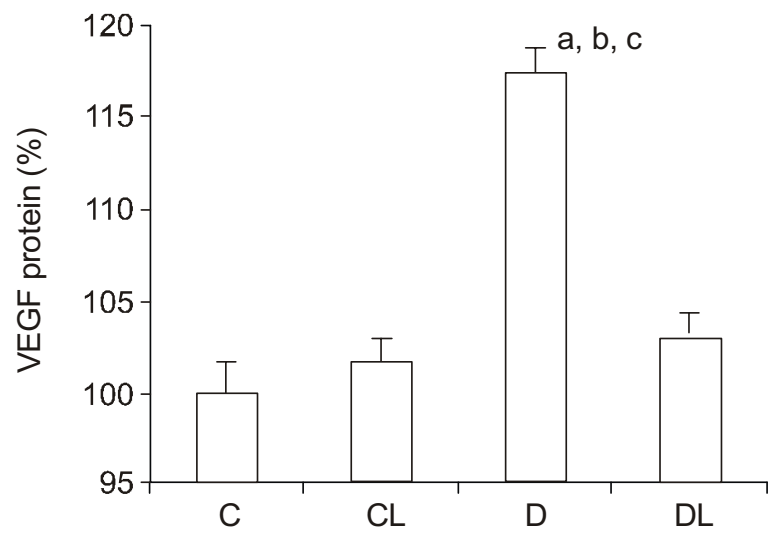

Figure 3. Immunohistochemical staining for VEGF in kidney from control rats $(C)$, control rats treated with L-158,809 (CL), diabetic rats (D), and diabetic rats treated with L-158,809 (DL). VEGF appeared to be confined within the glomerular podocytes (arrows) $(\times 400)$. Positive staining is shown as brown. The expression of VEGF was assessed by densitometric evaluation of the images by computer-assisted image analysis. Glomerular VEGF expression was increased in untreated diabetic rats and restored in L-158,809-treated diabetic rats. ${ }^{a} P<0.05$ vs. $C,{ }^{b} P<0.05$ vs. $\mathrm{CL},{ }^{\mathrm{c}} P<0.05$ vs. DL.

which induce angiogenesis and markedly increase microvascular permeability. VEGF is abundantly expressed in the renal glomerulus, specifically within the podocytes. This study has clearly demonstrated the potential clinical significance of angiotensin II-induced VEGF expression by podocytes in the pathogenesis of diabetic nephropathy (Williams, 1998).
Angiotensin II-induced VEGF gene expression was inhibited by the specific angiotensin II receptor antagonist L-158,809, confirming that this is an event mediated by angiotensin II type-1 receptors. These results describe a new action of angiotensin II on podocytes, notably the induction of VEGF expression. The potent activity of VEGF suggests a novel mech- 
anism whereby angiotensin II could locally and directly influence the vascular permeability independent of changes in hemodynamics (Williams et al., 1995).

In conclusion, experimental diabetes is associated with an increase in glomerular podocyte VEGF expression and renal permeability to protein. Treatment with antagonists to angiotensin II type-1 receptors in diabetic rats abolished the diabetes-associated VEGF increase and proteinuria. These findings implicate the reninangiotensin system in the VEGF overexpression and proteinuria that accompany diabetic nephropathy, and provide a potential mechanism for the beneficial effects of angiotensin II receptor antagonist in diabetic kidney.

\section{Acknowledgment}

This work was supported by grant no. R05-2002-00000024-0 from the Basic Research Program of the Korea Science \& Engineering Foundation.

\section{References}

Blantz RC, Gabbai FB. Effect of angiotensin II on glomerular hemodynamics and ultrafiltration coefficient. Kidney Int Suppl 1987;20:S108-11

Bunag RD. Validation in awake rats of a tail-cuff method for measuring systolic pressure. J Appl Physiol 1973;34:279-82

Cha DR, Kim NH, Yoon JW, Jo SK, Cho WY, Kim HK, Won $\mathrm{NH}$. Role of vascular endothelial growth factor in diabetic nephropathy. Kidney Int Suppl 2000;77:S104-12

Cooper ME, Vranes D, Youssef S, Stacker SA, Cox AJ, Rizkalla B, Casley DJ, Bach LA, Kelly DJ, Gilbert RE. Increased renal expression of vascular endothelial growth factor (VEGF) and its receptor VEGFR-2 in experimental diabetes. Diabetes 1999;48:2229-39

de Vriese AS, Tilton RG, Elger M, Stephan CC, Kriz W, Lameire NH. Antibodies against vascular endothelial growth factor improve early renal dysfunction in experimental diabetes. J Am Soc Nephrol 2001;12:993-1000

Gilbert RE, Kelly DJ, Cox AJ, Wilkinson-Berka JL, Rumble JR, Osicka T, Panagiotopoulos S, Lee V, Hendrich EC, Jerums G, Cooper ME. Angiotensin converting enzyme inhibition reduces retinal overexpression of vascular endothelial growth factor and hyperpermeability in experimental diabetes. Diabetologia 2000;43:1360-7

Ha SW, Seo YK, Kim JG, Kim IS, Sohn KY, Lee BH, Kim $B W$. Effect of high gulcose on synthesis and gene expression of collagen and fibronectin in cultured vascular smooth muscle cells Effect of high gulcose on synthesis and gene expression of collagen and fibronectin in cultured vascular smooth muscle cells. Exp Mol Med 1997;29:59-64

Hoshi S, Nomoto K, Kuromitsu J, Tomari S, Nagata M. High glucose induced VEGF expression via PKC and ERK in glomerular podocytes. Biochem Biophys Res Commun 2002; 290:177-84
Kretzler M, Schroppel B, Merkle M, Huber S, Mundel P, Horster M, Schlondorff D. Detection of multiple vascular endothelial growth factor splice isoforms in single glomerular podocytes. Kidney Int Suppl 1998;67:S159-61

Kriz W, Hackenthal E, Nobiling R, Sakai T, Elger M, Hahnel B. A role for podocytes to counteract capillary wall distension. Kidney Int 1994;45:369-76

Lane PH, Steffes MW, Mauer SM. Estimation of glomerular volume: a comparison of four methods. Kidney Int 1992; $41: 10851089$

Leehey DJ, Singh AK, Alavi N, Singh R. Role of angiotensin II in diabetic nephropathy. Kidney Int Suppl 2000;77:S93-8

Lynch KM, Sellers TS, Gossett KA. Evaluation of an automated pyrogallol red-molybdate method for the measurement of urinary protein in rats. Eur $\mathrm{J}$ Clin Chem Clin Biochem 1996;34:569-71

Mundel P, Kriz W. Structure and function of podocytes: an update. Anat Embyol (Berl) 1995;192:385-97

Nagisa $\mathrm{Y}$, Shintani A, Nakagawa $\mathrm{S}$. The angiotensin II receptor antagonist candesartan cilexetil (TCV-116) ameliorates retinal disorders in rats. Diabetologia 2001;44:883-8

Nelson RG, Meyer TW, Myers BD, Bennett PH. Clinical and pathological course of renal disease in non-insulin-dependent diabetes mellitus: the Pima Indian experience. Semin Nephrol 1997;17:124-31

Otani A, Takagi H, Suzuma K, Honda Y. Angiotensin II potentiates vascular endothelial growth factor-induced angiogenic activity in retinal microcapillary endothelial cells. Circ Res 1998;82:619628

Pagtalunan ME, Miller PL, Jumping-Eagle S, Nelson RG, Myers BD, Rennke HG, Coplon NS, Sun L, Meyer TW. Podocyte loss and progressive glomerular injury in type II diabetes. J Clin Invest 1997;99:342-8

Parving $\mathrm{HH}$, Kastrup J, Smidt UM. Reduced transcapillary escape of albumin during acute blood pressure-lowering in type 1 (insulin-dependent) diabetic patients with nephropathy. Diabetologia 1985;28:797-801

Pavenstadt H. Franz Volhard Award 2000: angiotensin II signalling in the podocyte. Kidney Blood Press Res 2000;23:156-8

The EUCLID Study Group. Randomised placebo-controlled trial of lisinopril in normotensive patients with insulin-dependent diabetes and normoalbuminuria or microalbuminuria. Lancet 1997;21:1787-92

Tsuchida K, Makita Z, Yamagishi S, Atsumi T, Miyoshi H, Obara S, Ishida M, Ishikawa S, Yasumura K, Koike T. Suppression of transforming growth factor beta and vascular endothelial growth factor in diabetic nephropathy in rats by a novel advanced glycation end product inhibitor, OPB-9195. Diabetologia 1999;42:579-88

Williams B, Baker AQ, Gallacher B, Lodwick D. Angiotensin II increases vascular permeability factor gene expression by human vascular smooth muscle cells. Hypertension 1995;25:913-7

Williams B. A potential role for angiotensin II-induced vascular endothelial growth factor expression in the pathogenesis of diabetic nephropathy? Miner Electrolyte Metab 1998; $24: 400-5$ 